\title{
ERRATUM
}

\section{Consensus guideline on parental methadone use in pain and palliative care}

\author{
LAUREN SHAIOVA, M.D., ${ }^{1}$ ANN BERGER, M.D., ${ }^{2}$ CRAIG D. BLINDERMAN, M.D., M.A., ${ }^{3}$ \\ EDUARDO BRUERA, M.D., ${ }^{4}$ MELLAR P. DAVIS, M.D., F.C.c.P., ${ }^{5}$ SUSAN DERBY, N.P., ${ }^{6}$ \\ CHARLES INTURRISI, PH.D., 7 JILL KALMAN, M.D., ${ }^{8}$ DEVENDRA MEHTA, M.D., PH.D., F.R.C.P., ${ }^{9}$ \\ MARCO PAPPAGALLO, M.D., ${ }^{10}$ AND EUGENE PERLOV, M.D. ${ }^{11}$ \\ ${ }^{1}$ Department of pain Medicine and Palliative Care, Metropolitan Hospital Center, Health and Hospital Corporation of \\ New York City, New York, New York \\ ${ }^{2}$ Pain and Palliative Care Physician, Bethesda, Maryland \\ ${ }^{3}$ Palliative Care Service, Department of Medicine, Massachusetts General Hospital and the Harvard Medical School \\ Center for Palliative Care, Boston, Massachusetts \\ ${ }^{4}$ Department of Palliative Care and Rehabilitaion Medicine, University of Texas MD Anderson Cancer Center, Houston, \\ Texas \\ ${ }^{5}$ Harry R. Horvitz Center for Palliative Medicine, Cleveland Clinic Foundation, Cleveland, Ohio \\ ${ }^{6}$ Pain and Palliative Care Service, Memorial Sloan-Kettering Cancer Center, New York, New York \\ ${ }^{7}$ Weill Cornell Medical College, New York, New York \\ ${ }^{8}$ Cardiovascular Institute, Mount Sinai Medical Center, New York, New York \\ ${ }^{9}$ Section of Cardiac Electrophysiology, Mount Sinai Hospital and School of Medicine, New York, New York \\ ${ }^{10}$ Mount Sinai School of Medicine, New York, New York \\ ${ }^{11}$ Visiting Nurse Service of New York Hospice Care, New York, New York
}

(Volume 6, Number 2, 2008, Pages 165-176; doi:10.1017/S1478951508000254)

Due to a production error, the wrong affiliation for Lauren Shaiova was given. The above is the correction affiliation for all authors in this article. 